\title{
If you believe that breaking is possible, believe also that fixing is possible: a framework for ruptures and repairs in child psychotherapy
}

\author{
Aviv Nof, Tohar Dolev, Liat Leibovich, Judith Harel, Sigal Zilcha-Mano \\ Department of Psychology, University of Haifa, Haifa, Israel
}

\begin{abstract}
Safran and Muran's classic theoretical framework of alliance rupture and repair suggests effective techniques for repairing alliance ruptures. Accumulating empirical evidence suggests that successful processes of rupture and repair result in better therapeutic outcome and reduced dropout rates. Although ruptures in the alliance in child psychotherapy are frequent, little is known about how to repair them. The present paper proposes a model for identifying and repairing ruptures in child psychotherapy based on Safran and Muran. It consists of four phases: i) identifying the rupture and understanding its underlying communication message, ii) indicating the presence of the rupture, iii) accepting responsibility over the therapists' part in the rupture and emphasizing the children's active role as communicators of their distress, and iv) resolving the rupture using change strategies and meta-communication by constructing a narrative story. The theoretical rationale of each phase is explained in detail, and practical clinical guidelines are provided. Empirical studies are needed to examine the effectiveness of the proposed framework.
\end{abstract}

Key words: Therapeutic alliance; Alliance ruptures and repairs; Child psychotherapy; Negotiation of alliance rupture.

\section{Introduction}

The working alliance is one of the most researched constructs in psychotherapy. Decades of empirical studies sug-

Correspondence: Sigal Zilcha-Mano, Department of Psychology, University of Haifa, Mount Carmel, Haifa 31905, Israel.

E-mail: sigalzil@gmail.com

See online Appendix for additional material.

Citation: Nof, A., Dolev, T., Leibovich, L., Harel, J., \& Zilcha-Mano, S. (2019). If you believe that breaking is possible, believe also that fixing is possible: a framework for ruptures and repairs in child psychotherapy. Research in Psychotherapy: Psychopathology, Process and Outcome, 22(1), 45-57. doi: 10.4081/ripppo.2019.364

Contributions: the authors contributed equally.

Conflict of interest: the authors declare no potential conflict of interest.

Funding: the writing of this paper was supported by the Israel Science Foundation (ISF).

Received for publication: 26 December 2018.

Revision received: 3 March 2019.

Accepted for publication: 4 March 2019.

This work is licensed under a Creative Commons Attribution NonCommercial 4.0 License (CC BY-NC 4.0).

(C) Copyright A. Nof et al., 2019

Licensee PAGEPress, Italy

Research in Psychotherapy:

Psychopathology, Process and Outcome 2019; 22:45-57

doi:10.4081/ripppo.2019.364 gest that the working alliance is the most consistent predictor of treatment outcome, across psychotherapy orientations, such that stronger alliance is associated with better treatment outcome (Flückiger, Del Re, Wampold, \& Horvath, 2018). Alliance is defined as the emotional bond established between the patient and the therapist, and the agreement between them on the goals of therapy and the tasks required to achieve them (Bordin, 1979). The accumulating research suggest that the alliance may serve both as the facilitating environment required for conducting any effective treatment and as an active ingredient, therapeutic in itself (CritsChristoph, Gibbons, \& Mukherjee, 2013; Muran, Safran, \& Eubanks-Carter, 2010; Zilcha-Mano, 2017).

The first generation of alliance research focused mainly on establishing the association between strong alliance and better treatment outcome. It was the second generation of research, initiated by Safran and Muran's (2000) classical work, that delved into the question of what makes alliance therapeutic, and how therapists may utilize the products of alliance research in their clinical practice. Safran and Muran's theoretical conceptualization of rupture and repair in the therapeutic alliances has greatly advanced both the empirical work on alliance and the implications of such work for actionable guidelines in clinical practice (Safran \& Muran, 2000).

A rupture in the alliance is defined as deterioration or tension in the alliance, manifested by a disagreement between the patient and therapist on the goals of treatment, lack of collaboration on tasks, or strain in the emotional bond (Eubanks, Muran, \& Safran, 2018). Ruptures in the alliance are common, and generally considered to be normal, inevitable events in the therapeutic process (Safran, Muran, \& Eubanks-Carter, 2011). The ability of 
the therapists to identify and resolve ruptures is a key factor associated with good outcome (Eubanks, Burckell, \& Goldfried, 2018; Safran \& Kraus, 2014; Safran \& Muran, 2000).

A central idea emerging from Safran and Muran's work is the importance of therapists recognizing ruptures or problems in the relationship, and using a therapeutic and supportive attitude in handling them (Safran, Crocker, McMain, \& Murray, 1990). Ruptures can be of two main subtypes: withdrawal and confrontational (EubanksCarter, Muran, \& Safran, 2015; Safran \& Muran, 2000). The withdrawal ruptures include two subtypes: move away and move toward. Move away withdrawal ruptures are characterized by avoidance and emotional disengagement from the therapist. It is manifest in long silences, minimal responses, changing the subject of the conversation, or abstract intellectual talk (Safran \& Muran, 2000). The move toward withdrawal rupture is characterized by readily complying with the therapist, at the cost of denying the patient's experience. The patients may express compliance and appeasement, being at the same time excessively deferential and overly submissive to the therapist and the treatment (Safran \& Muran, 2000). In confrontational ruptures, patients come out against the therapist and express anger.

Working through ruptures can play an important role as a corrective experience and as a new model for interpersonal growth (Safran et al., 2011). When working through ruptures in the alliance, therapists are encouraged to adopt a relational attitude, in which the patients' reactions of confrontation or withdrawal are not perceived exclusively as resistance and defensiveness, but mainly as opportunities for an important therapeutic work of repairing and resolving the rupture (Safran \& Muran, 2000). This relational dynamic of ruptures and repairs, which creates opportunities for change, rather than leading to a deadlock, is neatly expressed in the saying of Rabbi Nachman of Breslov: "If you believe that breaking is possible, believe also that fixing is possible."

Whereas most of the literature on the working alliance has focused on adult psychotherapy, there is accumulating literature suggesting the important role of the working alliance in child psychotherapy. The alliance has been found to be significantly associated with therapy outcome in child and adolescent psychotherapy, with small to medium effect sizes, that varied as a function of patient diagnosis, type of therapy, study design, and treatment setting (Karver, Nadai, Monahan, \& Shirk, 2018; McLeod, 2001). Alliance formation and maintenance in child psychotherapy has the potential to help clinicians in achieving positive outcomes in youth psychotherapy across disorders (Karver et al., 2018). Furthermore, the alliance was identified as a main contributor to discontinuing treatment in child psychotherapy (Garcia \& Weisz, 2002; Zack, Castonguay, \& Boswell, 2007). These findings are of great importance given the alarming dropout rate from child psychotherapy, of up to $60 \%$ (Baruch, Vrouva, \& Fearon, 2009; Midgley \& Navridi, 2006).

Several inherent features of psychotherapy with children can impair the therapeutic relationship at the beginning of treatment and throughout its entire course (Karver et al., 2018). These include the presence of multiple alliances that may affect one another (i.e., child-therapist and parents-therapist), and the cognitive capabilities of the child, which are still in the process of development (e.g., concrete thinking and centralization; Piaget, 1953). Therefore, techniques building on mature cognitive abilities (e.g., transference interpretation) may not be effective with children.

The use of alliance interventions in child psychotherapy is important, given the challenges that Shirk and Karver (2003) described when comparing alliance formation in adults and children. Unlike adults, children rarely seek treatment on their own initiative, often do not acknowledge the existence of problems, and do not agree with their parents on the goals of therapy.

The unique characteristics of ruptures and repair in the alliance with children suggest that alliance rupture and repair techniques developed in adult psychotherapy need to be tailored for working with children. Although much has been written about general treatment considerations and adjustments needed in child psychotherapy (e.g., Baggerly, Ray, \& Bratton, 2010), little is known about techniques to form and maintain strong alliances in child psychotherapy (exceptional examples are DiGiuseppe, Linscott, \& Jilton, 1996; Shirk, Karver, \& Brown, 2011).

The present paper introduces the Child Alliance Focused Approach (CAFA; "CAFA" is the Hebrew equivalent of a high five, expressed in the slapping of hands, which symbolizes the same opposite potential consequences that ruptures in the alliance do: a stronger bond or a disconnect), based on the framework proposed by Safran and Muran for repairing alliance ruptures in adult psychotherapy (Safran $\&$ Muran, 2000). The CAFA model can be used as a treatment in itself, or as a separate module in an existing treatment. In our work, the CAFA model is being developed as a central module of child supportive-expressive therapy (Child SE), which is based on the well supported SE for adults (Book, 1998; Horvath \& Luborsky, 1993). The CAFA model proposes techniques for identifying and repairing ruptures in the alliance between the child and the therapist, in individual child psychotherapy.

\section{The general Child Alliance Focused Approach model of ruptures resolution}

The CAFA is a model of clinical intervention designed to identify and repair ruptures in the alliance between the child and therapist. It is aimed at opening an interpersonal space of reflection and negotiation, in which a mutual recognition and relational change can occur, in a similar manner to the framework suggested in adult psychother- 
apy by Safran and Muran (Safran \& Muran, 2000). The CAFA model (see the figure in the Appendix) is based on a four-step process tailored specifically to child psychotherapy: identifying and understanding the rupture, indicating the presence of the ruptures, affirmation and metacommunication.

\section{Child Alliance Focused Approach phase one: identifying and understanding the ruptures}

\section{Theoretical consideration}

Successful rupture resolution involves opposing processes of embedding and dis-embedding from the rupture dynamics. As Muran, Safran and Eubanks-Carter (2010) argued, to be able to resolve the enactment, therapists must first get in, then know how to get out of it. The first phase in CAFA is aimed at stepping out of the rupture dynamics by helping therapists: i) regulate their affect and focus on the rupture that is taking place, ii) identify the type of rupture, and iii) self-reflect on the underlying communication message of the rupture.

The literature (Eubanks, Burckell, et al., 2018; Hofmann, Schmeichel, \& Baddeley, 2012) has stressed the importance of the first aim: the therapist being able to regulate affect successfully and focus directly on the alliance rupture, rather than continue with treatment as usual. Alliance research has demonstrated the efficacy of focusing on resolving the rupture resolution even if it means deviating from other treatment tasks, because continuing with "techniques as usual" may further erode the alliance (Eubanks et al., 2018). Furthermore, pausing and deliberately inhibiting dominant, automatic responses when necessary are important strategies for effective self-regulation (Hofmann et al., 2012). Pausing can be perceived as natural, and the literature supports the idea that nonverbal communication, including features of vocal rhythms, pauses, and silences occur in psychotherapy (Levitt, 2011; Seligman \& Harrison, 2012). As part of spoken language, pauses convey different meanings in psychotherapy, including emotions, reflexive thinking, and expressive mode (Levitt, 2011). We suggest that in the CAFA model, the pause used by the therapist can signal to patients that a rupture is taking place, and serve as a respectful gesture toward the child, showing an attempt to handle it in a controlled way. Harrison and Tronick (2011) noted that in child psychotherapy pauses are a conscious technique that can produce a rhythmic, turn-taking pattern, and convey willingness to be interrupted (Harrison \& Tronick, 2011).

The second aim, identifying and understanding the rupture, is based on the theoretical conceptualization according to which identifying the ruptures helps in avoiding the maladaptive vicious cycle of patient-therapist dynamics (Eubanks, Burckell, et al., 2018; Safran \& Kraus, 2014). Ruptures can take place "under the radar" and remain unnoticed by the therapist because children's enactments dur- ing ruptures can pull in the therapists, without their awareness, into the children's maladaptive relational patterns. In these situations, therapists need to extricate themselves from this vicious cycle, beginning by gaining awareness of the dynamics (Muran et al., 2010).

Similarly to adult psychotherapy, in child psychotherapy, ruptures may be easily missed by the therapist because they reflect patterns of maladaptive relational reactions, also referred to as "enactive relational representations" (Lyons-Ruth et al., 1998). Such maladaptive patterns often disguise the original intention of the children, who instead of expressing directly their needs, unconsciously pantomimes their conflictual theme in the therapeutic relationship (Book, 1998). Because of their fear of alienating others, people often suppress their true needs and desires in a way that leads to what Safran and Muran (2000) termed as pseudo-relatedness. In these cases, the therapist's role is to identify the ruptures and not to go along with the patient's (children's) tendency not to assert their needs and to relate to others in an unauthentic way (Safran \& Muran, 2000; Silberschatz, 2012).

Safran and Muran (2000) distinguished between two main markers of ruptures, which can help therapists in identifying them: withdrawal and confrontation. The withdrawal markers represent pseudo-relatedness. Withdrawal ruptures can be easily missed by the therapists because the children seem to cooperate, but in a way that deny their true needs, desires, and experience. The therapist may also mistakenly perceive the withdrawal marker as a general temperamental tendency of emotional dullness or diffused attention (e.g., constant topic changes), and not as reactive ruptures events. Confrontation markers are often easier to detect than withdrawal ones because the child overtly expresses dissatisfaction. However, the risk of inadequately identifying and responding to the rupture still exists, because the therapist's defenses can at times block the detection of a rupture. A direct attack can trigger narcissistic defensive reactions on the part of the therapist, which can hinder the rupture detection and resolution.

Given the elusive nature of ruptures, it is critical for the therapists to have strategies for identifying them. Focusing on countertransference markers can be one such effective strategy. Because children do not always communicate their distress verbally, countertransference could reflect the non-verbal cues of ruptures. The use of the countertransference information can help symbolize the unspoken states, making it possible for the therapist to react in new ways that do not reenact the vicious cycle (Bonovitz, 2009; Newhill, Safran, \& Muran, 2003).

The therapist's reflection and understanding of the underlining meaning of the rupture is a key ingredient in rupture resolution (Muran et al., 2010) because it can trigger important processes that may eventually lead to an adaptive asserting of interpersonal wishes and needs by the patients (Safran \& Muran, 2000). In adult psychotherapy, the reflection and understanding of the meaning of ruptures is 
achieved by exploratory questions that lead to metacommunication dialogues (Safran \& Muran, 2000). With children, however, the reflection and understanding of ruptures may be achieved by other strategies, better adapted to the children's developmental levels. The therapists reflection about the rupture should be an inner processes of mentalization in which the therapist translate within himself the overt behavior of the child into terms of the underlining meaning of the behavior (Harel, Kaplan, Avimeir-Patt, \& Ben-Aaron, 2006). The therapist's inner-reflection processes on the ruptures are a special case of inner self-talk (as opposed to a proper dialogue) about the origins of the rupture. It has been shown that self-talk plays a critical role in observing, monitoring, and directing behavior (Shi, Brinthaupt, \& McCree, 2015). Based on attachment conceptualizations (Marvin, Cooper, Hoffman, \& Powell, 2002), a reflection process can help the therapist translate the children's enactments during ruptures into distress signals and a longing for protection in a safe haven encounter (Bowlby, 1978). Such translation of the child's enactments into attachment needs uncovers the child's wishes and can help the therapists maintain an empathic understanding of the child's needs. An empathic stance, in turn, can enhance the alliance, and based on the safe haven provided by the therapists, also help children communicate their needs in more adaptive ways.

We suggest practical guidelines to achieve the three aims that constitute the first phase, consisting of identifying and understanding the rupture: regulating the therapists' affect and focus on the rupture, identifying the rupture and self-reflecting on its underlying message. The practical guidelines include pausing, marker identification, and reflection. All these processes are taking place inside the therapists as a result of inner reflection, without reacting outwardly to the child

\section{Clinical practice guidelines}

\section{Pausing}

Therapists are advised to stop the ongoing flow of the session and react in a regulated manner, focusing on the alliance rupture. The decision to pause should be in response to the experience of a salient shift in the child's behavior and experience or in the therapist's countertransference experience, for example, a feeling that the child cooperates too much or a feeling of sudden distraction in the part of the therapist. After identifying the shift, the therapist is advised to stop everything for few seconds, generally up to one minute. Therapists may consider verbalizing their need to pause for few seconds (e.g., "Before going on with the card game, I need few seconds to figure out how to continue. Is that OK?"). This declaration can help the child to ascribe a benevolent quality to the intervening pause.

\section{Marker identification}

Therapists are advised to keep in mind prototypical markers of withdrawal and confrontation ruptures with children, and to identify when one of these markers appear. Therapists should be aware that children can display withdrawal markers in several main forms: reluctance to participate in emotional exploration, choosing to play without sharing (on their own), showing signs of boredom, repeatedly checking the time, or sleepiness. Therapists should also be aware that typical answers such as "everything is OK" often represent withdrawals ruptures. Note that the move toward type of withdrawal rupture marker can easily go unnoticed. It is crucial to identify these move toward ruptures and respond to them, because with the inefficient move toward strategy of signaling, the children's distress may not be noticeable.

By contrast, confrontation markers are more noticeable and more easily identified because of their characteristic acting-out quality. Therapist should notice behaviors such as leaving the room, interrupting the therapist when talking, blunt expressions, insulting the therapist, or challenging the constraints imposed by the setting.

Therapists should also be aware of their own countertransference experience as markers of ruptures. Both prolonged negative feelings and the emergence of new negative feelings can attest to ruptures. When experiencing prolonged stretches of lack of enthusiasm, or a tendency to be distracted or angry, therapists should wonder whether a prolonged rupture is waiting to be resolved. When therapists experience flashes of feelings such as sadness or a desire to end the session, they should ask themselves whether a rupture is under way.

It is possible to identify withdrawal ruptures using the countertransference markers through the self-awareness of such feelings as boredom, emptiness, frustration, and a depressed mood. The countertransference information about the therapist own floating experience, feeling bored or not connected to what seems as an involved child, is a significant marker of the move toward withdrawal rupture, and can point to a cleavage between the overt behavior (cooperating) and the covert message of the move toward rupture.

It is possible to identify confrontation ruptures using countertransference markers through self-awareness of such feelings as anger, fear, avoidance (readily canceling session when possible), and possibly aggressive emotions. It is recommended that therapists monitor their countertransference experiences of impatience, anger, and even possible hatred or resentment toward the child. Such experiences of countertransference can attest to more than usually severe rupture dynamics, or to an ongoing rupture dynamic that includes helplessness as well as negative emotions and cognitions on both sides.

\section{Self-reflection on the underlying communication message of the ruptures}

The third practical guideline advises therapists to reflect on the meaning of the rupture and search for the underlying covert message the child is trying to 
communicate (e.g., need to be respected). Therapists should mentalize and reflect upon the meaning of the ruptures, without yet sharing it with the child. We recommend using the following four questions as part of the reflection step (designated by the acronym RNRN - Reason, Needs, Reaction, Non-adaptive pattern):

i) What preceded the rupture? (Reason)

ii) What did the child need from the therapist? (Needs)

iii) How did the child react to the rupture? (Reaction)

iv) Is the rupture part of a general vicious cycle? (Nonadaptive pattern).

\section{Clinical exchange demonstrating this phase}

George (all identifying details have been disguised) is an 8-year-old boy diagnosed with attention deficit disorder, in treatment to improve his self-confidence and his emotional regulation capacity. At the time the session took place (the fourth session), the therapist and the patient had already established a strong benevolent alliance, and the therapist recognized the preferred activities of the child (talking was not one of them). The following vignette has been excerpted from the fourth session. The therapist, who was extremely tired, did not offer the patient to play, instead asked him a lot of questions.

Ned (therapist): So, how was your week, George?

George (looking at a ball): OK

Ned: Can you say more?

George: Just OK, everything was OK.

Ned: What was OK?

George (looking around nervously): Everything.

At this point, the therapist recognized a disruption in the flow of experience, and following the pause guideline stopped and said: "Sorry George, I am a bit confused and need a few seconds to organize my thoughts. OK?". Ned regulated his feelings by pausing and focusing on the rupture resolution. He recognized his own countertransference of feeling frustrated; trying to squeeze water from a stone, and recognized the patient's markers of withdrawal rupture (George was not cooperating and not answering).

As part of the last step, self-reflection, Ned relieved his frustration using the self-talk technique, which helped him translate George's behavior into distress terminology. Ned was sad now (instead of frustrated) to know that George is feeling distressed. Using the RNRN questions, Ned formulated the following hypotheses: George reacted to a rupture in the alliance with withdrawal markers. This was his way to signal his distress about Ned's failure to acknowledge his needs (the attachment rationale in the therapist's self-talk). Ned realized that he had asked too many questions about George experiences, which intruded upon George's private space (question 1: reasons), and understood that George needed him to adjust in accordance to the signals of distress, and to respect George's pace and temperament (question 2: needs). George's reluctance and passive withdrawal from the interaction (question 3: reaction) was an enactment of his non-adap- tive pattern (question 4: non-adaptive pattern) of responding to insensitive demands by not asserting his needs and by withdrawing.

\section{Child Alliance Focused Approach phase two: indicating the presence of the ruptures}

\section{Theoretical consideration}

After identifying and understanding the rupture in the first phase, it is important to objectively declare and indicate that a rupture is present, and not to ignore it. Safran and Muran (2000) emphasized the importance of verbally indicating the presence of a rupture in the alliance, because people are often unaware to what they are implicitly responding. The therapist's main effort is to step outside the interaction and when appropriate communicate with the patient about the implicit transaction of the moment (Safran \& Kraus, 2014).

Safran and Muran noted the importance of exploring the rupture by using questions that direct the patients' attention to the here and now of the therapeutic relationship or to their experience, such as "How are you feeling about what's going on between us right now?" (Safran \& Muran, 2000). The explorative questions are well suited to adults, but with children, these techniques must be adjusted.

Two child-tailored interventions can be proposed in child psychotherapy: simple description and the summarizing metaphor. An example of a simple description of the child's reaction to the rupture is "You didn't want to go on playing with me." This simple description mirrors the act and can help translate behaviors into meaning (Fonagy et al., 1996). The literature supports the use of accurate mirroring as an efficient way of building the alliance and strengthening the patients' self-structures (Ackerman, Hilsenroth, \& Matthew, 2010). The summarizing metaphor is a description of the child's response to the rupture using higher abstract categorization terms and metaphors that narrate the patient dynamics. This intervention is aimed at gaining insight and building coherent narratives (Nof, Leibovich, \& Zilcha-Mano, 2017). In child psychotherapy in particular, metaphors are developmentally appropriate intervention that at the same time create a non-threatening atmosphere (Bennett, 2008; Gordon, 2018).

\section{Clinical practice guidelines}

Therapists should indicate that a rupture occurred using descriptive objective terms, such as the actions and behavior of the patient. This should be accomplished without involving causal inferences, unless the children themselves mention such inferences. The description should be stated in positive form, avoiding mentioning what was not done. For example, "I can see you tap with your fingers on the table" and not, "I can see that you're not listening to me." It is possible to include an emotional 
label that describes the child's emotion in a qualified statement (e.g., "You seem to be angry"), but not with overvigilant and suspicious children, who can experience the emotional label as an intrusion.

The summarizing metaphor includes a title that represents a generalizing of the child's reaction. The following brief clinical example demonstrates the categorizing description. In this example, the therapist refused to play Twister with 7-year-old Mary (the Twister is appropriate game to child-parent sessions, but because of the physical contact involved it does not fit child-therapist sessions). In response, Mary went on to play with some dolls, pretending to cooperate, and five minutes later suddenly said to the therapist: "All psychologists are stupid and you are an extreme version of it." The therapist who recognized the confrontational marker checked, whether anger countertransference feelings were involved, then said with comforting tone and smile: "Hey, I think you kind of threw some tomato in my face," He smiled gently and waited for her to smile back. "You're saying insulting things to me. Mmm?" The tomato metaphor and the categorizing description (insult) helped Mary observe the incident from the outside. She stopped the enactment and assumed a sad look in response. This change made it possible to move on to the next phase.

\section{Child Alliance Focused Approach phase three: affirmation of the ruptures}

\section{Theoretical consideration}

Affirmation of the rupture by the therapist is a supportive intervention that has been shown to have beneficial effects in resolving ruptures (Aspland, Llewelyn, Hardy, Barkham, \& Stiles, 2008; Safran et al., 2011). Safran and Muran (2000) stressed the importance of assuming responsibility for the rupture in a non-blaming fashion. The therapist assuming responsibly can help patients express their emotional needs and assert themselves without the fear of damaging the relationship (Safran \& Muran, 2000). Assuming responsibility can also serve as an act of deep empathy, which is a central element in development according to self-psychology (Kohut, 1984, 2013). Given their developmental emotional need, children who in therapy may thrive as the result of an experience of affirmation, especially if they often feel the opposite, that is, being accused or misunderstood for the same behaviors of acting out and for withdrawal dynamics of the type that are associated with ruptures.

Affirmation requires that therapists enter a special emotional state in which they experience compassion toward the child in his agony, and empathize with the child's need to be acknowledged for this agony. This non-accusing self-responsibility is based on Safran and Muran's premise that although it takes two to make a rupture, it is the therapists' role to lead a resolution processes with the greatest sensitivity and compassion they can master (Ryan, Safran, Doran, \& Muran, 2012). We propose that the therapists' mental act of stepping out of a rupture dynamic involves a movement from a state of being stuck in a non-mentalizing role (as participants) to the state of a compassionate mentalizing caregiver (as therapists). Marvin et al.'s (2002) circle of security principle captures and demonstrates this desired change, which is expected to result in the compassionate stance: "Always be bigger, stronger, wiser, and kind...Whenever possible, follow the child's need...Whenever necessary, take charge" (Marvin et al., 2002, p. 109). Based on clinical experience in supervising clinicians, we suggest that during intense emotional rupture incidents it is useful for therapists to recall the above attachment rationale and act accordingly.

Another key factor in the affirmation intervention is rephrasing the rupture into an active effort of the children to signal their distress. The original and often unconscious intention of the children should be transformed into a story of active effort to signal and communicate. The active emphasis conveys the relational state into which we would like the child to step, as a zone of proximal development (Vygotsky, 1980) and intervention, even if the original unconscious enactment was not intentionally active. The active emphasis constitutes scaffolding that helps children start communicating and become actively and adaptively agents of their inner wishes and needs (Book, 1998; Safran \& Muran, 2000).

\section{Clinical practice guidelines}

More than any other strategy, the affirmation intervention should be applied with genuine intention, not merely as a sequential technical stage. It requires sincere compassion to follow the child's need by being "bigger, stronger, wiser, and kind" (Marvin et al., 2002). When this is not possible, therapists are advised to skip to the next phase, and simultaneously consult with supervisors for alternative rupture resolution strategies.

Implementation of the affirmation strategy starts by catching the child's attention or wait for an encounter in which the child's attention directed to where the therapist is attending (Sebanz, Bekkering, \& Knoblich, 2006). We recommend making a declaration about having something important to say as an opening statement to focus the child's attention. Next, the therapist should state the affirmation statement, with emphasis on the therapist's responsibility for the rupture. Assuming responsibility is performed by explicitly explaining that the therapist's behavior or choice was not appropriate for the child, or that the therapist made a mistake by not reading correctly the situation. This affirmation should not include any explanation or interpretation of the child's part in the rupture. In other words, there should be no statements of the type: "You were angry because you felt I didn't listen carefully to you."

The therapist should make a short statement summa- 
rizing the event with descriptive elements, conveying the following message: "It is fully understood that you or any child would react with anger or some similar feeling to my failure of reading you correctly." At times, a gesture of apology should be considered if the emotional atmosphere is intense, especially with vulnerable narcissistic children. We recommend making it brief, and using it only in extreme cases because it might close the opportunity for the child to feel hurt and further explore the rupture.

Therapists should emphasize and validate the active effort of the children to assert their needs and wishes, making it easier for the children to send out distress signals (e.g., "You helped me know that you didn't like my long explanations" or "Thank you for showing me how you would like to..."). The child's effort is stressed by using the word "you" and by the use of active intention semantics, such as "you showed me," "you taught me what you need," "you let me know," "you helped me understand." Therapists may also express appreciation of the child's efforts, which helped them understand their mistake (e.g., "You felt uneasy about what I said, and you let me know it; it was very brave of you to do this, and it helped me understand my mistake").

The four elements of the affirmative intervention (catching the child's attention, self-responsibility, active form, and appreciation) should all be introduced in one coherent statement to achieve the desired effect. The following example demonstrates such coherent narrative: "Dan, I'd like to say something that is really important for me. Is it OK?" After Dan agrees: "Thanks. I think I made a mistake when I tried to convince you to play the emotional game. I didn't stop soon enough, and it was really a pain for you. I guess I'd also get angry if I were you. It's very important that you let me know about it. It helped me understand what you need here."

The therapist should continue the affirmation efforts for as long as the child signals that the affirmation is needed. The therapist could repeat the affirmation statement at the end of the session in which it was used, and return to it at the following few sessions, when appropriate (e.g., when another rupture occurs).

\section{Child Alliance Focused Approach phase four: resolving the ruptures using the change strategy and meta-communication}

\section{Theoretical consideration}

Resolving the rupture is an in-session act that requires the patient's consent, as do all other goals and tasks in treatment. Asking permission to talk about sensitive themes has been recognized as a collaboration enhancing intervention (Moyers, Miller, \& Hendrickson, 2005). Safran and Muran (2000) developed a typology model for resolution strategies. The model describes different pathways of intervention, organized on two levels of interven- tion: surface and depth. The surface level can be either direct or indirect. The direct surface intervention involves clarifications of the treatment rationale or of the misunderstanding between the therapist and the patient. The indirect surface intervention involves changing a treatment task or goal in the case of disagreement (Safran, Muran, \& Eubanks-Carter, 2011).

At the deep level, the therapists explore the core relational theme and provide a new relational experience. The deep level includes metacommunication strategies which are processes of communicating with the patient about the implicit transaction taking place in the therapeutic relationship (Safran \& Muran, 2000). The metacommunication is aimed at rising above the current rupture to provide patients the opportunity to begin communicating their wishes and needs (Safran \& Kraus, 2014). In a process of negotiating the rupture dynamics with the therapist, the meta-communication strategies can help patients gain insight into their relational patterns.

The typology Safran and Muran proposed with regard to adults is also relevant for child psychotherapy, with some adjustments.

The surface interventions in CAFA are similar to Safran and Muran's guidelines (Safran \& Muran, 2000), with emphasis on a highly flexible attitude in applying changes taking into account the child's signals, because of the unique features of a child's developmental characteristics (e.g., short attention span). The surface level can be especially beneficial with younger children, under the age of 6-7, because of their relative concrete way of analyzing reality (Piaget, 1952). When concrete thinking meets the concrete surface rupture resolution of an actual change, the children feel that they are understood and that their language is being spoken in the therapy room. For example, in the course of dyadic psychotherapy, if the child shows dissatisfaction and wants his parents to leave the room, after discussing it with the parents, the therapist makes the change and switches to individual meetings, without further interpretation.

Therefore, the surface resolution should focus on changing the setting, the tasks, or the goals of treatments. We suggest that the surface intervention should be well suited in all situations, including emotionally loaded exchanges and cases in which there is no need to delve into deeper emotional dynamics. This does not mean that the deep level intervention (the meta-communication story) should not be used later, in the same session, or in a subsequent one. We suggest that handling ruptures with the CAFA is to a great extent a matter of timing and attunement to the signals of the patient and the therapist's countertransference.

The deep level of resolution, which includes the metacommunication strategies, requires more substantial adjustments to make it suitable to the abilities and needs of children. We propose to convert the meta-communication strategies into a child-sensitive narrative intervention, 
which we call the meta-communication story. Narrative have been shown to be efficient intervention in child psychotherapy (Crowley \& Mills, 1986; Desocio, 2005), as it bypasses the use of direct interpretation, which is not always efficient or possible with children (Alvarez, 2010). White (2007) explained that narrative techniques enable therapists to provide children with new awareness of their problems and to help them experience personal agency over their problems. The narrative framework encourages externalizing the conflictual and sensitive themes (in our case, the vicious cycle of enactments), turning it into an outside problem and opening up a space for observation and enhancement of the sense of self-agency (Ramey, Tarulli, Frijters, \& Fisher, 2009).

We propose to focus the meta-communication story on the child's interpersonal wish from others (Book, 1998). The ability to realize the wish is a central goal in both supportive expressive (Book, 1998; Luborsky \& Crits-Christoph, 1998) and in alliance-focused therapy (helping patients express their underlying wish or need) (Safran \& Kraus, 2014; Safran et al., 2011). According to Book (1998), to facilitate the process of realizing the patient's wish it is important to raise the patient's awareness of how frequently and forcefully the conflict governs the patient's relationships (Book, 1998). The meta-communication story describes the child's wish as a journey based on Book's (1998) framework, starting from a state of unawareness of the maladaptive cycle of responses that freezes the wish in its unfulfilled form, and ending with awareness of the maladaptive responses and an ability to choose new paths of wish actualization.

The meta-communication story uses a terminology of "choosing" and "changing," which is part of the "change talk" (i.e., verbalization of desires, ability, reasons, need, and commitment), which has been reported to be an efficient way of enhancing changes (Miller \& Rollnick, 2012; Moyers et al., 2005). The meta-communication story may also include general normalizing statements about acceptable normal wishes and desires (e.g., all kids want their parents to let them be as they are and love them for who they are). Such statements have been found to serve as an efficient supportive intervention for self-acceptance (Misch, 2006).

Finally, based on our clinical experience, we recommend using what we call the "in here as opposed to outside" strategy. This strategy makes a clear distinction between what is accepted to be part of the therapy relationship and what may be accepted in the world outside of the therapy room. It conveys the message that "I can contain your angry feeling or insulting behavior toward me, but outside, kids will probably get angry and hurt you." This strategy may be suited for narcissistic vulnerable children because it keeps the therapeutic relationship secure and non-threatening, but at the same time it projects the self-disclosure elements onto others and does not neglect it.

\section{Clinical practice guidelines}

The first guideline is to ask permission to talk about the rupture. We call asking such permission a "knocking at the door" strategy. A rupture is by definition a sensitive event and experience, therefore the therapist should ask permission to talk about it and be open to being refused.

The meta-communication story should be prepared in advance in its general form (usually no later than the forth session), then adapted to the specific context when it is delivered. The prototype story includes four elements: i) the hero of the story as a remoted figure in a remote place or time (e.g., "I once read a book about an Australian girl, Nicole, who liked kangaroos very much, but had some issues with friends; she was a very sensitive girl); ii) the wish and its unfulfilled form (e.g., Nicole, the Australian girl, wanted very much to have close friends, but something was bothering her); iii) an exaggerated description of the maladaptive response of the child to the unfulfilled wish (e.g., "So Nicole decided to play with kangaroos all days; she didn't want to be hurt or rejected. All day she played just with kangaroos. It was fun at the beginning but, you know, kangaroos all day?"); iv) The change that the child underwent to actualize her wish by choosing to take a risk (e.g., "Nicole talked with her grandma, Iris, who told her she should turn into a kangaroo-like girl. Granma Iris explained that the kangaroos are very strong animals and could survive on their own if they wanted to, but they prefer to socialize. You know, darling, when kangaroos don't like something or someone, they just jump away, but they always go back and try to reconnect. It's risky, Nicole, you know? The kangaroos take the risk whenever they come back, they can be insulted again, but I think it's worth it. After all, kangaroos always have friends, no? Why is that? Because they always come back to check and try again").

The therapist should identify the wish by recalling and reflecting on information from the RNRN questions (the reflection phase in the CAFA), or by recalling other exchanges reflecting the disguised wish dynamics (e.g., the patient's efforts to win by cheating reflects her wish to be appreciated). The story should use content from the child's spheres of interests (e.g., figures from video games, animals the child likes), and it should be as interesting as possible. It should contain emotional words and descriptions of extreme reactions (e.g., the girl was so angry when her aunt didn't say goodbye after that lunch, and did not want to meet her aunt ever again).

As illustrated in the following clinical exchange, surface level resolution may be beneficial for younger children. May (fictitious name), a 6-year-old girl, was treated for generalized anxiety disorder. At the first session, Eli, the psychologist, started with a short psychoeducation explanation, using pictures, about relaxation methods according to child CBT protocol he was following. May got bored and interrupted Eli: "My stomach hurts, can I have some tea?" Eli stopped talking and decided to follow the 
surface changes by changing the tasks. He prepared a cup of tea, and began working on bonding with May emotionally. He started playing with her and showing interest in her, without the psychoeducation explanations (which came later on).

\section{Discussion and Conclusions}

The framework for alliance ruptures and repairs developed by Safran and Muran is an empirically supported approach for handling alliance ruptures, which is suitable for a variety of therapeutic orientations (Eubanks et al., 2018), but to the best of our knowledge, has never been adapted to child psychotherapy. The CAFA model proposed in this article adapts the conceptual principles and practical techniques suggested by Safran and Muran to child psychotherapy, answering the call for effective manualized short-term interventions for children (Abbass, Rabung, Leichsenring, Refseth, \& Midgley, 2013). The CAFA provides therapists with clear, applicable repair strategies tailored to children.

The CAFA model includes four phases (shown in the Appendix). In the first phase, therapists are instructed to identify the rupture. Their objective is to achieve three aims: regulate therapist affect while focusing on the rupture that is taking place, identify the type of rupture, and selfreflect on the underlying communication message of the rupture. In the second phase, therapists are instructed to indicate the presence of the rupture. In the third phase, therapists are instructed to accept responsibility for the rupture without assigning blame, and to rephrase the rupture as an active effort on the part of the children to signal their distress. Finally, in the fourth phase, therapists are provided with tools for resolving the ruptures using a change strategy and meta-communication story intervention.

As is generally the case in child psychotherapy, when implementing the CAFA module, it is important to do so in parallel with parent training. Parent training is often considered a key element of treatment continuation and success (Deakin, Gastaud, \& Nunes, 2012; Harel et al., 2006; Martinez, Lau, Chorpita, \& Weisz, 2017; Whitefield \& Midgley, 2015). The formation and maintenance of a strong alliance with parents is often a highly complex task. We believe that a module that parallels the CAFA should be developed for parent training. Until such a module is developed, we propose that the original guidelines of Safran and Muran be used to guide therapists in the task of forming alliance with the parents.

The CAFA should be employed with flexibility and not as a rigid sequence of four phases. In some cases, fewer than four phases are needed, and the order of the phases may vary. The main indication that it is necessary to change or end the CAFA sequence is that the children signal their distress. For example, when a child reacts with anger and frustration during the indication phase, the therapists may consider stopping implementation of this phase, and either return to the previous phase or switch to some other technique.

The CAFA is best suited for children aged 6-17. Children with depression, anxiety, oppositional defiant disorder and attention deficit hyperactivity disorder can benefit the most from the CAFA, as a module added to treatments based on various types of child psychotherapy orientations (e.g., CBT and psychodynamic). Because ruptures are prevalent in any psychotherapy encounter, any child psychotherapy may benefit from CAFA to resolve ruptures.

The CAFA is a general model for rupture and repair strategy in child psychotherapy, which should be adjusted to the developmental level of the child. We propose following Piaget's (1952) stages of cognitive development together with more contemporary developmental empirical findings (e.g., Berk, 2017) as a general map for making the necessary adjustments to the CAFA.

With children aged 6-7, considered to be in the preoperational stage (Piaget, 1952), we recommend using a more concrete and direct approach to rupture resolution, specifically, surface level changes (Safran \& Muran, 2000); for example, if the child does not want to talk much, it is advisable to consider changing the task.

Another adjustment at this age (6-7 years) should be made to the meta-communication story, which should contain direct explanations, using play therapy techniques and a dramatization of the rupture, for example, with puppet animals. Play therapy techniques of this type allow children to bridge the gap between their experiences and understanding, and provide insights about emotionally complex issues (Bratton, Ray, Rhine \& Jones, 2005). With children aged 7-11, considered to be in the concrete operational stage (Piaget, 1952), we recommend considering using the CAFA model as is, being well suited to the symbolic abilities of school-age children. With emotionally and cognitively mature children, aged 12-16, we recommend considering using the adult rupture and repair framework of Safran and Muran (2000). Children of this age share a high level of abstraction and logical thinking with adults (formal operational stage; Piaget, 1952). The therapist may choose a tailored integration of the CAFA model with the adult rupture resolution model that best fits the given child. The differential use of the CAFA according to the stages of the child's cognitive levels should be investigated in future studies, and especially the preoperational stage adjustments.

The pausing sub-phase of the intervention should be suited to the developmental level of children and to the unique temperamental tendencies of each child. Originally, CAFA therapists who use the pause try to convey a message of respect and attunement by reflecting upon the rupture. Younger children, however, up to around the age of 10 , might not fully understand the pauses as a mental act with a special benevolent intention. Before the age of 10 , children might demonstrate immature levels of theory of mind, may not be capable of mature perspective-taking or 
of understanding of how people act on based on their beliefs, emotions, and intention (Flavell, Green, \& Flavell, 2000). It has been shown that preschoolers cannot consistently attribute a mental activity to a person who just sits quietly (Flavell, Grenn, \& Flavell, 1993, 1995). Therefore, with children aged 6-10 it is recommended to avoid long pauses; instead, it is preferable to use a statement like "something has happened here" as an act of making sense of the event, then move to the next stage of the CAFA. In contrast, by age of 10, children may start to regard the mind as an active constructive agent, and develop a mature theory of mind (Flavell, 2000; Berk, 2017). From this age onward the pause can become an effective intervention.

The pausing guideline may not suit certain temperaments. For example, children with a high novelty-seeking temperamental profile look for new and unknown experiences, are impulsive, curious, and easily bored (Kang \& Kwack, 2018; Melegari et al., 2015). These children may need other, more energetic intervention than pausing to match their fast inner pace. Future studies should explore these needed adjustments to CAFA for children with unique temperamental tendencies.

Some populations of children may require special adaptations of the CAFA from the outset. With children with high levels of self-vulnerability who exhibit non-empathic relational attitudes, we recommend omitting the affirmation intervention because validation of their point of view may deepen their potentially narcissistic tendencies. In these cases, we propose making a special effort to implement intervention that emphasize that although it is understood that a mistake has been made (partial affirmation of the rupture), there should be a difference and a clear boundary between the inner feeling and doing things that hurt others on the outside.

Further CAFA adjustments should be considered in relation to externalization and internalization problems, and to the mentalization capacity of the children. Children may differ in their ability to form alliance, depending on such characteristics as externalizing or internalizing presenting problem (Shirk and Karver, 2003). Younger patients with immature mentalization ability may benefit from integration of the CAFA with mentalization oriented play therapy (Halfon and Bulut, 2017; Sharp, Fonagy, \& Goodyer, 2006). With older children who suffer from externalization problems, the meta-communication story can be transformed into a direct conversation, starting with validating the child's experience about the rupture and with psychoeducation-oriented meta-communication that focuses on regulation skills and perspective-taking intervention. Such directive meta-cognitive skills have been shown to be effective in treating children who suffer from behavioral problems (Masi et al., 2014; Kazdin, 2018). With more maturely mentalizing children who suffer from internalizing disorders, the abstract symbolic form of metaphors and the meta-communication story intervention can be more applicable, because children suffering from internalizing problems seem to respond better to psychodynamic intervention than do children suffering from disruptive or externalizing disorders (Fonagy \& Target, 1996; Midgley \& Kennedy, 2011).

We suggest that there is a possible association between the type of diagnosis and the typical ruptures that are possible. Based on clinical experience, we suggest that children with externalizing problems may produce more confrontative ruptures with the therapists, whereas children who suffer from internalizing problems (e.g., depression) may produce more withdrawal ruptures. The related countertransference that each type evokes may be different (e.g., anger or fear with the externalizing-confrontative type and sadness or hopelessness with the internalization-withdrawal type). The therapist's characteristics may also affect the type of rupture. In any case, both types should be understood as a signal of distress and a call for rupture resolution.

The CAFA was developed to provide therapists with tools to identify and resolve ruptures in child psychotherapy. This is an important goal given the high prevalence of dropout from child psychotherapy, which was found to be associated with impaired alliance. Indeed, most children who start treatment drop out before receiving the help that they need (Kazdin, 1996; Martinez et al., 2017, Midgley \& Navridi, 2006). The implementation of repair techniques in adult psychotherapy has reduced dropout rates (Muran et al., 2005), and it is reasonable to assume that the CAFA has the potential to do the same for child psychotherapy.

Although the CAFA is based on the empirically supported framework developed by Safran and Muran, it needs to be empirically tested on its own. The CAFA should be empirically investigated in future studies using RCT design with such tools as the Therapy Process Observational Coding System-Alliance scale (TPOCS-A; McLeod, 2001), as an empirically validated measure capable of objectively describing child and parent alliance with the therapist across both the bond and task dimensions (McLeod, 2001; Mcleod \& Weisz, 2005). Future work should investigate the utility of the CAFA in relation to specific rupture types (the move away and move toward withdrawal and the confrontation type). Special attention should be paid to certain sub-populations that may benefit most from CAFA and to specific situations in treatment when it is needed most. The need to understand what works for whom, why and how, can bring empirical studies closer to the complexity of human life (Zilcha-Mano, 2018) and help us develop better treatments for children.

\section{References}

Abbass, A. A., Rabung, S., Leichsenring, F., Refseth, J. S., \& Midgley, N. (2013). Psychodynamic psychotherapy for children and adolescents: A meta-analysis of short-term psychodynamic models. Journal of the American Academy of Child and Adolescent Psychiatry, 52(8), 863-875. 
Ackerman, S. J., Hilsenroth, M. J., \& Matthew, R. (2010). Interaction of therapeutic process and alliance during psychological assessment. Journal of Personality Assessment, 75(1), 82-109. doi: 10.1207/S15327752JPA7501.

Alvarez, A. (2010). Levels of analytic work and levels of pathology: The work of calibration. International Journal of Psychoanalysis, 91(4), 859-878. doi: 10.1111/j.1745-8315. 2010.00284.

Aspland, H., Llewelyn, S., Hardy, G., Barkham, M., \& Stiles, W. (2008). Alliance ruptures and rupture resolution in cognitivebehavior therapy: A preliminary task analysis. Psychotherapy Research, 18(6), 699-710. doi: 10.108010503300802291463.

Baggerly, J. N., Ray, D. C., \& Bratton, S. C. (2010). Child-centered play therapy research: The evidence base for effective practice. Hoboken, NJ, US: John Wiley \& Sons.

Baruch, G., Vrouva, I., \& Fearon, P. (2009). A follow-up study of characteristics of young people that dropout and continue psychotherapy: Service implications for a clinic in the community. Child and Adolescent Mental Health, 14(2), 69-75. doi: 10.1111/j.1475-3588.2008.00492.x

Bennett, L. (2008). Narrative methods and children: Theoretical explanations and practice issues. Journal of Child and Adolescent Psychiatric Nursing, 21(1), 13-23. doi: 10.1111/ j.1744-6171.2008.00125.x

Berk, L. (2017). Development through the lifespan. Pearson Education India. Child Development, 64, 387-398.

Bonovitz, C. (2009). Countertransference in child psychoanalytic psychotherapy: the emergence of the analyst's childhood. Psychoanalytic Psychology, 26(3), 235-245. doi: $10.1037 / \mathrm{a} 0016445$.

Book, H. E. (1998). How to practice brief psychodynamic therapy: The core conflictual relationship theme method. Washington, DC: American Psychological Association Press.

Bordin, E. S. (1979). The generalizability of the psychoanalytic concept of the working alliance. Psychotherapy: Theory, Research \& Practice, 16(3), 252.

Bowlby, J. (1978). Attachment theory and its therapeutic implications. Adolescent Psychiatry, 6, 5-33.

Bratton, S. C., Ray, D., Rhine, T., \& Jones, L. (2005). The efficacy of play therapy with children: A meta-analytic review of treatment outcomes. Professional Psychology: Research and Practice, 36(4), 376.

Crits-Christoph, P., Gibbons, M. B. C., \& Mukherjee, D. (2013). The efficacy and effectiveness of psychotherapy. Bergin and Garfield's Handbook of Psychotherapy and Behavior Change (6th Ed., Pp. 298-340). New York, NY: Wiley.

Crowley, R. J., \& Mills, J. C. (1986). The nature and construction of therapeutic metaphors for children. British Journal of Experimental \& Clinical Hypnosis, 3(2), 69-76.

Deakin, E., Gastaud, M., \& Nunes, M. L. T. (2012). Child psychotherapy dropout: An empirical research review. Journal of Child Psychotherapy, 38(2), 199-209. doi: 10.1080/0075417X.2012.684489

Desocio, J. E. (2005). Approaches in child and adolescent psychotherapy. Journal of Child and Adolescent Psychiatric Nursing, 18(2), 53-62.

DiGiuseppe, R., Linscott, J., \& Jilton, R. (1996). Developing the therapeutic alliance in child-adolescent psychotherapy. Applied and Preventive Psychology, 5(2), 85-100. doi: 10.1016/S0962-1849(96)80002-3

Eubanks-Carter, C., Muran, J. C., \& Safran, J. D. (2015). Alliance-focused training. Psychotherapy, 52(2), 169.
Eubanks, C. F., Burckell, L. A., \& Goldfried, M. R. (2018). Clinical consensus strategies to repair ruptures in the therapeutic alliance. Journal of Psychotherapy Integration, 28(1), 6076. doi: $10.1037 /$ int0000097.

Eubanks, C. F., Muran, J. C., \& Safran, J. D. (2018). Alliance rupture repair: A meta-analysis. Psychotherapy, 55(4), 508.

Flavell, J. H. (2000). Development of children's knowledge about the mental world. International Journal of Behavioral Development, 24(1), 15-23.

Flavell, J. H., Green, F. L., \& Flavell, E. R. (1993). Children's understanding of the stream of consciousness. Child Development, 64(2), 387-398.

Flavell, J., Green, F., \& Flavell, E. (1995). Young children's knowledge about thinking. Monographs for the Society for Researching Child Development, No. 60.1. Chicago: University Chicago Press.

Flavell, J. H., Green, F. L., \& Flavell, E. R. (2000). Development of children's awareness of their own thoughts. Journal of Cognition and Development, 1(1), 97-112.

Flückiger, C., Del Re, A. C., Wampold, B. E., \& Horvath, A. O. (2018). The alliance in adult psychotherapy: a meta-analytic synthesis. Psychotherapy, 1(2), 23951. doi: 10.1037/ pst0000172.

Fonagy, P., Leigh, T., Steele, M., Steele, H., Kennedy, R., Mattoon, G., ... Gerber, A. (1996). The relation of attachment status, psychiatric classification, and response to psychotherapy. Journal of Consulting and Clinical Psychology, 64(1), 22.

Fonagy, P., \& Target, M. (1996). Playing with reality: I. Theory of mind and the normal development of psychic reality. International Journal of Psycho-Analysis, 77, 217-233.

Garcia, J. A., \& Weisz, J. R. (2002). When youth mental health care stops: Therapeutic relationship problems and other reasons for ending youth outpatient treatment. Journal of Consulting and Clinical Psychology, 70(2), 439-443. doi: 10.1037/0022-006X.70.2.439.

Gordon, T. J. (2018). Utilizing animal metaphors in child psychotherapy: an integrative approach for therapists. The Graduate Review, 3(1), 135-148.

Halfon, S., \& Bulut, P. (2017). Mentalization and the growth of symbolic play and affect regulation in psychodynamic therapy for children with behavioral problems. Psychotherapy Research, 1-13.

Harel, J., Kaplan, H., Avimeir-Patt, R., \& Ben-Aaron, M. (2006). The child's active role in mother-child, father-child psychotherapy: A psychodynamic approach to the treatment of relational disturbances. Psychology and Psychotherapy: Theory, Research and Practice, 79(1), 23-36. doi: 10.1348/147608305X52577.

Harrison, A. M., \& Tronick, E. (2011). “The Noise Monitor” a developmental perspective on verbal and nonverbal meaning-making in psychoanalysis. Journal of the American Psychoanalytic Association, 59(5), 961-982.

Hofmann, W., Schmeichel, B. J., \& Baddeley, A. D. (2012). Executive functions and self-regulation. Trends in Cognitive Sciences, 16(3), 174-180. doi: 10.1016/j.tics.2012.01.006.

Horvath, A. O., \& Luborsky, L. (1993). The role of the therapeutic alliance in psychotherapy. Journal of Consulting and Clinical Psychology, 61(4), 561.

Kang, N. R., \& Kwack, Y. S. (2018). Temperament and character profiles for children with ADHD with and without tic disorders. Psychiatry Research, 270, 281-285.

Karver, M. S., Nadai, A. S. De, Monahan, M., \& Shirk, S. R. (2018). Meta-analysis of the prospective relation between 
alliance and outcome in child and adolescent psychotherapy. Psychotherapy, 55(4), 341-355. doi: 10.1037/pst0000176.

Kazdin, A. E. (1996). Dropping out of child psychotherapy: Issues for research and implications for practice. Clinical Child Psychology and Psychiatry, 1(1), 133-156.

Kazdin, A. E. (2018). Implementation and evaluation of treatments for children and adolescents with conduct problems: findings, challenges, and future directions. Psychotherapy Research, 28(1), 3-17.

Kohut, H. (1984). How does analysis cure. Chicago, IL: University of Chicago.

Kohut, H. (2013). The analysis of the self: A systematic approach to the psychoanalytic treatment of narcissistic personality disorders. Chicago: University of Chicago Press.

Levitt, H. M. (2001). Sounds of silence in psychotherapy: The categorization of clients' pauses. Psychotherapy Research, 11(3), 295-309.

Luborsky, L., \& Crits-Christoph, P. (1998). Understanding transference: The core conflictual relationship theme method. Washington, DC, US: American Psychological Association.

Lyons-Ruth, K., Bruschweiler-Stern, N., Harrison, A. M., Morgan, A. C., Nahum, J. P., Sander, L., ... Tronick, E. Z. (1998). Implicit relational knowing: Its role in development and psychoanalytic treatment. Infant Mental Health Journal: Official Publication of The World Association for Infant Mental Health, 19(3), 282-289.

Martinez, J. I., Lau, A. S., Chorpita, B. F., \& Weisz, J. R. (2017). Psychoeducation as a mediator of treatment approach on parent engagement in child psychotherapy for disruptive behavior. Journal of Clinical Child and Adolescent Psychology, 46(4), 573-587. doi: 10.1080/15374416.2015.1038826

Marvin, R., Cooper, G., Hoffman, K., \& Powell, B. (2002). The Circle of Security project: Attachment-based intervention with caregiver-pre-school child dyads. Attachment \& Human Development, 4(1), 107-124.

Masi, G., Milone, A., Paciello, M., Lenzi, F., Muratori, P., Manfredi, A., ... Muratori, F. (2014). Efficacy of a multimodal treatment for disruptive behavior disorders in children and adolescents: Focus on internalizing problems. Psychiatry Research, 219(3), 617-624.

McLeod, B. D. (2001). The therapy process observational coding system for child psychotherapy. Los Angeles: University of California.

McLeod, B. D., \& Weisz, J. R. (2005). The therapy process observational coding system-alliance scale: measure characteristics and prediction of outcome in usual clinical practice. Journal of Consulting and Clinical Psychology, 73(2), 323.

Melegari, M. G., Nanni, V., Lucidi, F., Russo, P. M., Donfrancesco, R., \& Cloninger, C. R. (2015). Temperamental and character profiles of preschool children with ODD, ADHD, and anxiety disorders. Comprehensive Psychiatry, $58,94-101$.

Midgley, N., \& Kennedy, E. (2011). Psychodynamic psychotherapy for children and adolescents: a critical review of the evidence base. Journal of Child Psychotherapy, 37(3), 232-260.

Midgley, N., \& Navridi, E. (2006). An exploratory study of premature termination in child analysis. Journal of Infant, Child, and Adolescent Psychotherapy, 5(4), 437-458. doi: 10.1080/15289160701382360

Miller, W. R., \& Rollnick, S. (2012). Motivational interviewing. Helping people change. New York, NY, US: Guilford Press.
Misch, D. A. (2006). Basic strategies of dynamic supportive therapy. Focus, 9(2), 173-268.

Moyers, T. B., Miller, W. R., \& Hendrickson, S. M. L. (2005). How does motivational interviewing work? Therapist interpersonal skill predicts client involvement within motivational interviewing sessions. Journal of Consulting and Clinical Psychology, 73(4), 590-598. doi: 10.1037/0022006X.73.4.590

Muran, J. C., Safran, J. D., \& Eubanks-Carter, C. (2010). Developing therapist abilities to negotiate alliance ruptures. In J. C. Muran \& J. P. Barber (Eds.), The therapeutic alliance: An evidence-based guide to practice (pp. 320-340). New York, NY, US: The Guilford Press.

Muran, J. C., Safran, J. D., Samstag, L. W., \& Winston, A. (2005). Evaluating an alliance-focused treatment for personality disorders. Psychotherapy, 42(4), 532-545. doi: 10.1037/0033-3204.42.4.532

Newhill, C. E., Safran, J. D., \& Muran, J. C. (2003). Negotiating the therapeutic alliance: A relational treatment guide. New York, NY, US: Guilford Press.

Nof, A., Leibovich, L., \& Zilcha-Mano, S. (2017). Supportiveexpressive interventions in working through treatment termination. Psychotherapy, 54(1), 29-36. doi: 10.1037/ pst000009

Piaget, J. (1953). How children form mathematical concepts. Scientific American, 189(5), 74-79.

Ramey, H. L., Tarulli, D., Frijters, J. C., \& Fisher, L. (2009). A sequential analysis of externalizing in narrative therapy with children. Contemporary Family Therapy, 31(4), 262-279. doi: 10.1007/s10591-009-9095-5.

Ryan, A., Safran, J. D., Doran, J. M., \& Muran, J. C. (2012). Therapist mindfulness, alliance and treatment outcome. Psychotherapy Research, 22(3), 289-297. doi: 10.1080/ 10503307.2011.650653.

Safran, J. D., Crocker, P., McMain, S., \& Murray, P. (1990). Therapeutic alliance rupture as a therapy event for empirical investigation. Psychotherapy: Theory, Research, Practice, Training, 27(2), 154.

Safran, J. D., \& Kraus, J. (2014). Alliance ruptures, impasses, and enactments: A relational perspective. Psychotherapy, 51(3), 381-387. doi: 10.1037/a0036815.

Safran, J. D., \& Muran, J. C. (2000). Resolving therapeutic alliance ruptures: Diversity and integration. Journal of Clinical Psychology, 56(2), 233-243.

Safran, J. D., Muran, J. C., \& Eubanks-Carter, C. (2011). Repairing alliance ruptures. Psychotherapy, 48(1), 80.

Sebanz, N., Bekkering, H., \& Knoblich, G. (2006). Joint action: bodies and minds moving together. Trends in Cognitive Sciences, 10(2), 70-76.

Seligman, S., \& Harrison, A. (2012). Infancy research, infant mental health, and adult psychotherapy: Mutual influences. Infant Mental Health Journal, 33(4), 339-349.

Sharp, C., Fonagy, P., \& Goodyer, I. M. (2006). Imagining yourchild's mind: Psychosocial adjustment and mothers'ability to predict their children's attributional response styles. British Journal of Developmental Psychology, 24(1), 197-214.

Shi, X., Brinthaupt, T. M., \& McCree, M. (2015). The relationship of self-talk frequency to communication apprehension and public speaking anxiety. Personality and Individual Differences, 75, 125-129. doi: 10.1016/j.paid. 2014.11.023

Shirk, S. R., \& Karver, M. (2003). Prediction of treatment outcome from relationship variables in child and adolescent 
therapy: A meta-analytic review. Journal of Consulting and Clinical Psychology, 71, 452-464.

Shirk, S. R., Karver, M. S., \& Brown, R. (2011). The alliance in child and adolescent psychotherapy. Psychotherapy, 48(1), 17-24. doi: 10.1037/a0022181

Silberschatz, G. (2012). Transformative processes in psychotherapy: How patients work in therapy to overcome their problems. Psychotherapy in Australia, 18(4), 30-35.

Vygotsky, L. S. (1980). Mind in society: The development of higher psychological processes. Cambridge, MS - London, UK: Harvard University Press.

White, M. K. (2007). Maps of narrative practice. New York: WW Norton \& Company.

Whitefield, C., \& Midgley, N. (2015). 'And when you were a child?': how therapists working with parents alongside individual child psychotherapy bring the past into their work. Journal of Child Psychotherapy, 41(3), 272-292. doi: 10.1080/0075417X.2015.1092678.

Zack, S. E., Castonguay, L. G., \& Boswell, J. F. (2007). Youth working alliance: A core clinical construct in need of empirical maturity. Harvard Review of Psychiatry, 15(6), 278-288.

Zilcha-Mano, S. (2017). Is the alliance really therapeutic? Revisiting this question in light of recent methodological advances. American Psychologist, 72(4), 311.

Zilcha-Mano, S. (2018). Major developments in methods addressing for whom psychotherapy may work and why. Psychotherapy Research, 1-16. 